\title{
The 2005 International Psychogeriatric Association (IPA) Research Awards in Psychogeriatrics
}

This issue of the journal sees the publication of the 3 papers placed first, second and third in the 2005 International Psychogeriatric Association (IPA) Research Awards in Psychogeriatrics. For the first time in the history of the awards (first presented in 1989 and awarded at each biennial IPA Congress thereafter), entries were limited to junior investigators within five years of the award of their terminal degree who were at no higher than Assistant Professor/Instructor level at the time of submission. The awards were judged by a panel of four comprising Bengt Winblad (panel chair and 12th IPA Congress chair), David Ames (editor International Psychogeriatrics), John O'Brien (deputy editor International Psychogeriatrics and 12th IPA Congress Scientific Steering Committee Chair) and Joel Sadavoy (then President elect of IPA). The field comprised 11 papers from nine countries (Canada, China (including the Special Administrative region of Hong Kong), Greece, Egypt, the Netherlands, Serbia and Montenegro, Spain, Uganda and the U.S.A.) and contained several papers which in a less competitive field would have been worthy recipients of an award. In addition to the three award winning papers, in an unprecedented decision the judges approved a special citation for a fourth submission entitled "Psychiatric disorders among the elderly on non-psychiatric wards in an African setting" by Noeline Nakasujja of Uganda for "Outstanding Research Endeavors undertaken in a previously un-researched field, in the face of unusual operational challenges." The winners received travel and accommodation expenses to allow them to attend the 12th Congress of IPA in Stockholm and were given an opportunity to present their work to the Congress audience in the opening plenary session. In addition, as has been traditional, their papers were accepted for publication in International Psychogeriatrics. The importance of the Research Awards to the journal is underlined by the fact that the first and second placed 2003 IPA Research Award winning papers (Storey et al., 2004; Lai et al., 2004) were downloaded from the journal website more often than any other paper in the fist six months of 2005. I fully expect that as has been the case with previous IPA Research Award Winning Papers, that the three papers published in this issue will be among our most highly cited publications for 2006, and hope, that like some previous winners, these outstanding young researchers will go on to achieve leadership positions within IPA in particular and the discipline of psychogeriatrics in general. 


\section{DAVID AMES}

Editor-in-chief International Psychogeriatrics

Melbourne, Australia

Email: ipaj-ed@unimelb.edu.au

\section{References}

Lai, C. K. Y., Chi, I and Kayser-Jones, J. (2004). A randomized controlled trial of a specific reminiscence approach to promote the well-being of nursing home residents with dementia. International Psychogeriatrics, 16, 33-49. DOI:10.1017/S1041610204000055.

Storey, J. E., Rowland, J. T. J., Basic, D., Conforti, D. A. and Dickson, H. D. (2004). The Rowland Universal Dementia Assessment Scale (RUDAS): a multicultural cognitive assessment scale. International Psychogeriatrics, 16, 13-31.

DOI: $10.1017 /$ S1041610204000043. 